\title{
Comparison of Transformational Leadership Practices: Implications for School Districts and Principal Preparation Programs
}

\author{
Jeff Quin \\ Department of Technology/District Administration \\ Lawrence County School District \\ Aaron Deris \\ Assistant Professor, Department of Special Education \\ Minnesota State University \\ Greg Bischoff \\ Adjunct Professor \\ Northcentral University \\ James T. Johnson \\ Director of the Center for Research Support \\ University of Southern Mississippi
}

\begin{abstract}
The purpose of this study was to determine the leadership practices needed to improve academic achievement and generate positive change in school organizations. The study was also conducted to provide insight to principal preparation programs and school districts about effective transformational leadership practices. A quantitative research method was used to achieve the survey study. Ninety-two teachers completed the Leadership Practices Inventory developed by Kouzes and Posner. Data was analyzed with the use of descriptive statistics and ttests. The findings of the study indicate that (a) principals in high performing schools employ all leadership practices more frequently than principals in lower performing schools and (b) inspiring a shared vision and challenging the process are the two practices that have the biggest impact on student achievement. It is recommended that principal preparation programs incorporate Kouzes and Posner's transformational leadership model into their curriculum in order to develop highly qualified school leaders.
\end{abstract}

\section{Introduction}

Accountability has been part of the educational landscape for the past five decades. Since the early 1990s, accountability has concentrated on issues of adequacy. The Goals 2000 and No Child Left Behind Act (NCLB) were enacted to increase academic achievement for all students and improve didactic institutions (Styron \& Styron, 2011). Even though accountability has been prevalent throughout the years, principal leaders continue to be unsuccessful at meeting the academic standards set by the state and federal accountability models (Dillon, 2010; Styron 
\& Styron, 2011). Many researchers have proposed principals are not being taught the needed leadership theory and skills for K-12 leadership roles (Huff et al.,2011; Styron \& Lemire, 2009; Versland, 2013). Versland (2013) indicated many leadership programs fail to connect theory to practice, provide effective internships and field experiences, and recruit high quality candidates. Davis and Darling-Hammond (2012) found principal preparation programs must provide a clear focus on the leadership practices and theory that will improve student learning. McKibben (2013) proposed that school districts should provide a pre-service program to develop and retain effective school leaders.

Principal Preparation Programs. School leadership is essential to the success of school organizations. Principals are rated second to teachers in the improvement of student achievement and they may explicate up to $25 \%$ of the variance in student learning (Davis \& Darling-Hammond, 2012; McKibben, 2013). In this new era of accountability, school leaders are expected to increase achievement and make substantial academic growth for all students. The reform of the didactic organization depends on the quality of principal leadership (Hess \& Kelly, 2005, McKibben, 2013). Effective principal preparation programs are key to the development of high quality school leaders (Hess \& Kelly, 2005; McKibben, 2013; Styron \& Lemire, 2009).

Research in the last 10 years suggests that traditional and alternative preparation programs are failing to prepare school principals for the leadership role. Maulding et al. (2010) suggested school districts around the nation are suffering from a shortage of qualified principal leaders. Finnigan (2010) stated a significant problem in failing schools is ineffective leadership. Studies indicate that school leadership programs are failing to prepare leaders with the skills required to successfully lead teachers and increase student achievement (Huff et al., 2011). According to Styron and Lemire (2009), traditional and alternative training programs in the United States lack the vision, purpose, structure, and unity needed to prepare leaders to improve curriculum, instruction, and achievement. Al-Omari \& Sharaah (2012) indicated leadership preparation programs in Turkey are not preparing principals for the responsibilities and duties needed to successfully generate positive change in the school organization. McKibben (2013) revealed conventional principal preparation programs lack a sound practice-based curriculum, rigor, and selection criteria for candidates.

Recently, studies by Davis and Darling Hammond (2012) and Perilla (2014) have provided insight into characteristics of an effective principal preparation program. Davis and Darling-Hammond (2012) conducted a study on five university-based principal preparation programs. The researchers examined several pieces of evidence to draw conclusions, such as (a) candidate and graduate perceptions about preparedness, (b) observations of graduates' practices on the job, and (c) student achievement data. The research team found the key elements of a leadership program include: a rigorous admission process, development of core leadership practices or skills, an evaluation process, development of leaders who can generate organizational change, alignment of leadership theory with practice, and effective internships with skilled supervision (Davis \& Darling-Hammond (2012). Perilla (2014) proposed school districts should provide high quality mentors to new principals along with professional development appropriate for the individual. A limitation of this study was that each of the essential characteristics of effective leadership programs were not examined. 
Leadership Practices and Transformational Leadership. Research has indicated specific leadership practices positively influence academic achievement and reform the didactic institution (Abu-Tineh, Khasawneh, \& Al-Omari, 2009; Crum, Whitney, \& Myran, 2009; Leithwood, Harris, \& Hopkins, 2008). Leithwood, Harris, and Hopkins (2008) declared effective leaders utilize a common set of leadership practices to transform school organizations. A number of studies were conducted to establish the most frequently employed leadership practices and skills of effective leaders. The leadership practices included setting directions, developing the capacity of staff, redesigning the educational institution, and managing the instructional program (Crum et al., 2009; Leithwood, Aitken, \& Jantzi, 2006; Leithwood et al., 2008). Kouzes and Posner (2007) discovered inspiring a shared vision, modeling the way, challenging the process, enabling others to act, and encouraging the heart were the leadership practices utilized regularly by successful transformational leaders.

Studies of Leadership Practices. An infinitesimal number of studies have been conducted on the comparison of transformational leadership practices in high performing and low performing schools. Knab (2009) conducted a survey study to determine the differences between the leadership practices of principals in high performing and low performing schools and concluded that a significant difference exists. Sawati, Anwar, and Majoka (2011) conducted a similar study and concluded that no significant difference existed in the leadership practices of principals in low performing and high performing schools. From available literature, it is debatable if a significant difference exists in the leadership practices of principals in high performing and low performing schools. This study was conducted to identify the difference in transformational leadership practices in high performing and low performing schools and contribute to the body of research on leadership theory.

Transformational Leadership. Research indicates that transformational leaders are capable of transforming the people and culture within an organization (Masumoto \& BrownWelty, 2009; Pepper, 2010). Kouzes and Posner (2007) proposed leaders who utilize transformational leadership practices make exemplary changes in an organization. Universities and alternative preparation programs must teach principals transformational leadership practices to prepare them to use accountability and achievement data to drive instruction, serve as an instructional coach, challenge the status quo, motivate and mentor staff, manage personnel, handle disruptions in and out of the school, and understand economic, social, technological, and global change on schooling (Sadeghi \& Pihie, 2012; Styron \& Lemire, 2009). The increasing demands of the principalship require leadership programs to make changes to their programs and curriculum. Kouzes and Posner (2007) indicated leadership programs should utilize a curriculum that includes a set of prescribed leadership practices.

Empirical research indicates that effective and capable transformational leaders are essential to the success of reform efforts (Al-Omari \& Sharaah; 2012, Knab, 2009; Pugh, Fillingim, Blackbourn, Bunch, \& Thomas, 2011). Principals in high performing schools generate positive change in their organization through building trust among the stakeholders and creating a healthy school culture (Leithwood et al., 2008; MacNeil, Prater, \& Busch, 2009). Principal leaders strengthen their culture through celebrating successes, telling success stories, and reinforcing the established standards and values (Turan \& Bektas, 2013). According to AbuTineh, Khasawneh, and Al-Omari (2009), school leaders in high performing schools transform 
their organization through improving the culture, motivation, and performance of the faculty and staff.

\section{Theoretical Framework}

Transformational leadership is the leadership theory that served as a model for this study. Transformational leadership is defined as a leadership strategy that generates reform in the stakeholders, school culture, and educational organizations (Burton \& Peachey, 2009). Chegini (2010) proposed principals who employed transformational leadership improved teacher performance and student achievement. Abu-Tineh et al. (2009) stated transformational leaders achieve extraordinary results by developing a shared vision, setting the example, challenging the status quo, and supporting staff.

Burns (1978) developed the conception of transformational leadership in 1978. Transformational leadership was considered a moral endeavor that raised the morale and motivation of the leader and followers to a higher level (Pepper, 2010). Bass employed the work of Burns to develop the Full Range Leadership Model (Hoy \& Miskel, 2008). The leadership model contained four transformational components, two transactional components, and laissezfaire leadership (Abu-Tineh et al., 2009). Transformational leaders are described as exhibiting inspirational motivation, intellectual stimulation, idealized influence, and individual consideration. The research team of Kouzes and Posner has refined our understanding of transformational leadership.

Transformational leadership, as identified by Kouzes and Posner (2007), served as the foundation of this study. The research team emphasized leadership is a set of learned practices that can be employed by any individual willing to make a difference. The transformational leadership practices allow the principal leader to achieve the goals set by the organization and obtain exceptional results. The five practices of effective leadership were established through investigating approximately 75,000 leaders over the past 30 years. The five transformational leadership practices include modeling the way, inspiring a shared vision, challenging the process, enabling others to act, and encouraging the heart (Abu-Tineh et al., 2009; Kouzes \& Posner, 2007).

Inspiring a Shared Vision. Successful leaders inspire a shared vision with their faculty and staff (Kouzes \& Posner, 2009). Constituents are committed to achieving the objectives of an organization when the vision is created collectively. Hallinger (2011) identified organizational vision as the key to improving student learning. Effective school leaders employ the shared vision to guide their staff and align resources to attain organizational goals (Kantabutra, 2010). A shared vision motivates the stakeholders to make informed decisions regarding instructional practices and stimulates the constituents to examine current organizational policies and practices (Kouzes \& Posner, 2009).

Modeling the Way. Effective leaders develop a clear set of values for constituents to follow (Gulcan, 2012). Transformational principals set the example and build loyalty through their daily actions. Principal leaders reveal their commitment to the stakeholders by setting a positive example. Faculty and staff are willing to follow a credible leader who lives by the 
values he or she supports (Abu-Tineh et al., 2009). Chegini (2010) proposed teacher performance improves dramatically when the school leader is seen engaging in the organization's shared vision and goals.

Challenging the Process. Exemplary school leaders generate new and novel ideas through challenging the process. The principal leader and faculty develop innovative reform efforts through experimentation and risk-taking (Sahin, 2011). Challenging the status quo allows the stakeholders to test their skills, learn new effective teaching strategies or procedures, and turn ideas into action (Abu-Tineh et al., 2009; Saban \& Wolfe, 2009). Finnigan (2010) declared leaders create positive change in the organization when they encourage staff to take the initiative. Abu-Tineh et al. (2009) proposed leaders and staff must make mistakes in order to open the door to new ideas and opportunities.

Enabling Others to Act. Successful leaders encourage staff to perform at their maximum potential by enabling them to act and lead. The school leader builds trust with the faculty by cultivating teamwork and support (Gulcan, 2012). An environment based on trust and self-respect allows stakeholders to create positive change at the classroom and organizational levels (Sahin, 2011). Roby (2011) asserted that high performing principal leaders support their staff members frequently and inspire their teachers to become leaders. Transformational leaders motivate their staff and teacher leaders to initiate reform efforts and develop new approaches to improve educator and student performance (Valentine \& Prater, 2011).

Encouraging the Heart. Teachers and staff need encouragement and inspiration to attain the goals of the organization. Abu-Tineh et al. (2009) indicated encouraging the heart is a fundamental practice in improving teacher performance and student learning. Transformational leaders influence job performance of teachers and staff members by utilizing incentives, celebrations, and recognition (Lee, 2008). The effective leader uses the encouraging the heart practice to increase teachers' sense of belonging, commitment, and drive to achieve the objectives of the didactic institution.

Kouzes and Posner (2007) proposed school leaders who use the five transformational leadership practices will generate positive educational reform and achieve exemplary results. Nash (2010) found successful leaders use transformational leadership practices to improve teacher performance and student achievement. Studies have shown that academic achievement is positively impacted by transformational leadership (Knab, 2009; Turan \& Bektas, 2013). It is hypothesized in this study that leaders in high performing schools utilize transformational leadership practices more effectively than principals in low performing schools and school performance is correlated with transformational leadership.

\section{Research Problem}

Principals from around the world continue to struggle with increasing student achievement (Styron \& Styron, 2011). Universities and principal preparation programs are not preparing school leaders with the leadership practices or skills necessary to be successful in the school setting (Huff et al., 2011). Thus, research is needed to develop a deeper understanding of the transformational practices required to prepare principals to reform the didactic institution and 
increase academic achievement. An assessment of the transformational leadership practices employed by principals in varying performing schools could provide universities with insight to improve their leadership programs.

\section{Purpose of the Study}

The purpose of the study was to assist universities in developing a deeper understanding of the transformational leadership practices needed to better prepare school leaders to generate positive change in their educational organizations. A second objective of this study was to determine the individual transformational leadership practices that would improve teacher performance and student achievement. A third aim of the study was to establish the differences in transformational leadership practices of principals in high performing and low performing schools. The following question guided the study:

RQ1. What is the difference between high and low performing schools on the five variables of leadership practices (modeling the way, inspiring a shared vision, challenging the process, enabling others to act, and encouraging the heart)?

The following hypothesis was tested:

H10. There is no significant difference between high and low performing schools on the five variables of leadership practices (modeling the way, inspiring a shared vision, challenging the process, enabling others to act, and encouraging the way).

\section{Methodology}

Research Design. The quantitative research study was executed with the use of an online survey. The survey study was cross-sectional because all data was collected at one point in time. A comparative design was employed to conduct the research. A comparative technique was appropriate for this study because the method allowed the researcher to determine differences among groups (Yan, 2009). A set of t-tests was utilized to determine the differences in leadership practices of principals in high performing and low performing schools.

Participants. Teachers from 10 school districts in Southwest Mississippi participated in this study. The study was conducted during the 2011-2012 school year. Mississippi schools obtain a performance level or Quality Distribution Index (QDI) based on the students' scores on the state assessments. The QDI is calculated from the percentage of students scoring basic, proficient, and advanced on the state assessments. The QDI is calculated by using the following formula: QDI $=($ Basic X 1) $+($ Proficient X 2) $+($ Advanced X 3$)$. The performance score or QDI of a didactic organization ranges from 0 to 300 (Mississippi Department of Education, Office of Accreditation, 2009). The seven accountability labels issued to school organizations during this study were (a) Star, (b) High Performing, (c) Successful, (d) Academic Watch, (e) Low Performing, (f) At Risk of Failing, and (g) Failing. Organizations labeled High Performing and Star were considered high performing organizations and those with the label of Failing, At Risk of Failing, or Low Performing were considered low performing schools (Mississippi Department of Education, Office of Research and Statistics, 2010). The Mississippi Department of Education (MDE) website was used to obtain student achievement or performance level data. 
An a priori power analysis was performed to establish the appropriate sample size for the investigation. The sample size was determined by assuming a power of .80, an alpha level of .05 , and an effect size of .35 (Coladarci et al., 2011). The resulting sample size for the analysis was 68 subjects. The study had a total of two groups. Thus, each group required a minimum of 34 participants. The minimum sample size was met with the smallest group in the study having a total of 43 participants.

A simple random sampling method was employed to select the participants. Approximately 130 teachers from elementary, middle, and high schools were chosen to participate in the study. Ninety-two teachers participated which resulted in a $71 \%$ response rate. Approximately $88 \%$ of the participants were female and $79 \%$ of the subjects were Caucasian.

Variables. The variables for this study included leadership practices and school performance. Leadership practices were conceptualized with the use of Kouzes and Posner's Transformational Leadership Model. The five leadership practices variables include modeling the way, inspiring a shared vision, challenging the process, enabling others to act, and encouraging the heart. The school performance variable was based on the 2011-2012 Mississippi state assessments. The school performance data was obtained from the MDE website. The five leadership practices were interval variables and the dependent variable in this study. School performance was a categorical variable based on the QDI of the didactic institution and was the independent variable for this investigation. High performing schools were coded as a 1 and low performing schools were coded as a 2.

Instrumentation. The Leadership Practices Inventory (LPI) by Kouzes and Posner (2003) was used to assess the leadership practices variables. The leadership practices measured with the LPI were (a) modeling the way, (b) inspiring a shared vision, (c) challenging the process, (d) enabling others to act, and (e) encouraging the heart. The LPI is based on a 10-point Likert-scale with response ranging from 1 (almost never) to 10 (almost always). High scores for a leadership practice indicate the leader is effective at that practice while low scores indicate the principal is not effective at that practice. The instrument consists of a total of 30 questions with six questions for each leadership practice. A minimum score of six and a maximum score of 60 can be attained for each leadership practice. The internal reliability as measured by Cronbach's Alpha was found to range from 0.85 to 0.92. Kouzes and Posner (2007) describe each leadership practice as follows: (a) modeling the way, the extent or degree to which the leader sets the example for the faculty and staff to follow; (b) inspiring a shared vision, the degree to which the leader develops a shared vision and mission with the stakeholders; (c) challenging the process; the extent to which the leader takes risks and experiments in order to generate positive change and achieve goals; (d) enabling others to act, the degree to which the leader supports and motivates the staff and empowers them to become leaders; and (e) encouraging the heart, the degree to which the leader recognizes staff for outstanding performance and celebrates organizational successes. 
Data Collection. The first step taken in the data collection process was to obtain permission from the superintendents, principals, and Northcentral University. Second, a simple random sampling procedure was used to obtain a random sample of participants. Ten participants were chosen from each school involved in the study. Thirteen schools participated in the study and a total of 92 teachers completed the survey. Third, the subjects were invited to participate in the study. An online survey was used to collect transformational leadership data. Fourth, a link to the online survey was sent to the participants through email. Follow-up email reminders were sent to the participants to increase the response rate. Data for the study was collected for approximately four weeks.

Data Analysis. The data was analyzed and statistically evaluated with the use of descriptive and inferential statistics. A set of t-tests was utilized to determine the differences in leadership practices of principals in high performing and low performing schools. The statistical test was appropriate for measuring the differences among principal groups.

\section{Results}

The purpose of this study was to determine the differences in leadership practices of principals in high and low performing schools. The mean and standard deviation was calculated for each of the leadership practices for principals in high and low performing schools. The descriptive statistics are presented in Table 1. The difference in the mean between the two principal groups for the five leadership practices ranged from 0.84 to 1.28 . The greatest difference in groups occurred with two leadership practices: challenging the process (1.28) and inspiring a shared vision (1.16). The descriptive statistics revealed that a difference exists between the two principal groups. A set of t-tests was conducted to determine if a significant difference actually existed between the principals in high performing and low performing schools.

The results of the t-tests are shown in Table 1. The t-tests reveal that a difference exists in the leadership practices between the two principal groups. The results signify that group differences were found for modeling the way $(\mathrm{t}(90)=2.81, \mathrm{p}=.006)$, inspiring a shared vision $(\mathrm{t}(90)=3.67, \mathrm{p}=<.001$, challenging the process $(\mathrm{t}(90)=4.04, \mathrm{p}=<.001$, enabling others to act $(t(90)=3.19, p=.002$, and encouraging the heart $(t(90)=3.62, p=<.001$. The findings of this study indicated a significant difference exists in all five leadership practices of principals in high performing and low performing schools. 
Table 1

ANOVA Analysis of the 5 Leadership Practices

\begin{tabular}{llllll}
\hline & $\begin{array}{l}\text { HP School } \\
(\mathrm{n}=43)\end{array}$ & $\begin{array}{l}\text { LP School } \\
(\mathrm{n}=49)\end{array}$ & & & \\
Leadership Practice & $M(S D)$ & $M(S D)$ & $d f$ & $t$ & $p$ \\
\hline Modeling the Way & $8.94(1.06)$ & $8.01(1.92)$ & 90 & 2.81 & .006 \\
Inspiring a Shared Vision & $9.13(0.97)$ & $7.97(1.87)$ & 90 & 3.67 & $<.001$ \\
Challenging the Process & $8.91(0.96)$ & $7.63(1.89)$ & 90 & 4.04 & $<.001$ \\
Enabling Others to Act & $8.98(0.99)$ & $7.96(1.89)$ & 90 & 3.19 & .002 \\
Encouraging the Heart & $8.89(1.14)$ & $8.05(2.07)$ & 90 & 3.62 & $<.001$ \\
\hline
\end{tabular}

Note. $\mathrm{N}=216 ; M=$ Mean, $S D=$ Standard Deviation, $\mathrm{df}=$ degrees of freedom, $\mathrm{HP}=$ High Performing, LP = Low Performing.

\section{Implications and Recommendations}

The transformational leadership practices of principals in high performing and low performing schools were investigated in this study. Kouzes and Posner's Transformational Leadership Model was used to conceptualize the leadership practices variables and served as the basis of this study. The findings of this investigation are discussed in this section. Furthermore, the implications of the results and recommendations for practice are presented.

Implications. From the literature review, it was discovered a limited amount of research had been conducted on the differences in the leadership practices of school leaders in varying performing organizations. Thus, there was a need to investigate leadership from high performing and lower performing schools in order to better understand the practices required to generate positive change and increase academic achievement. This research added to the lack of research on effective leadership practices in school organizations. Insight was also provided to universities concerning the transformational leadership practices needed to develop highly qualified principal leaders.

The findings of this study indicate principals in high performing schools utilize all five transformational leadership practices more regularly and effectively than leaders in low performing institutions. The greatest difference that occurred in leadership practices was with inspiring a shared vision and challenging the process. Thus, it is imperative principals in low performing organizations improve all leadership practices, particularly inspiring a shared vision and challenging the process. The findings of this study are supported by other researchers (AbuTineh et al., 2009; Knab, 2009; Saban \& Wolfe, 2009; Siegrist, Weeks, Pate, \& Monetti, 2009). Inspiring a shared vision is a practice identified as a key element in impacting staff motivation, generating change, and creating a healthy culture (Abu-Tineh et al., 2009; Saban \& Wolfe, 2009). Kouzes and Posner (2009) affirmed effective school leaders create a shared vision with 
the stakeholders in order to energize followers, develop a standard of excellence, and foster a commitment to academic excellence. The shared vision motivates the constituents in achieving the objectives of the didactic organization. In addition, a joint vision will encourage the stakeholders to buy into change efforts (Senge, 2008). Inspiring a shared vision behaviors that principals in low performing schools should improve include the following: (a) discussing future trends that will impact how work gets completed, (b) describing a compelling image of the future, (c) showing staff how long term interests will be accomplished by enlisting in a shared vision, (d) painting an image of desired achievements, and (e) communicating with conviction about the purpose and significance of their work (Kouzes \& Posner, 2003).

Challenging the process is the leadership practice that the low performing school leaders were least proficient. Therefore, principal leaders in low performing schools must employ these practices more frequently and effectively in the educational setting. Principals who challenge the process successfully will take more risks and search for new approaches to reform the organization (Abu-Tineh et al., 2009). Challenging the process is a daring practice that is required in order to make substantial improvements in student achievement. The challenging the process practices that school leaders in low performing schools should improve include: (a) seeking out opportunities to test the abilities of self and others, (b) challenging staff to attempt novel approaches to improve their work and student learning, (c) learning from mistakes, (d) experimenting and taking risks to improve performance, and (e) building consensus around a common set of values and beliefs (Kouzes \& Posner, 2003).

Recommendations for Practice. Recommendations for practice focus on professional development, training, and application. The results of this study reveal that school leaders in high performing schools practiced Kouzes and Posner's leadership practices at a high level while principals in low performing schools practiced the leadership practices at a moderate level. Thus, more emphasis needs to be placed on Kouzes and Posner's leadership practices in low performing schools. It is recommended that school leaders in low performing schools participate in trainings and professional learning communities in order to improve their leadership practices.

The most significant differences in leadership practices between high and low performing schools occurred with inspiring a shared vision and challenging the process. The results of this study indicated these two practices will have the biggest impact on student achievement. Therefore, principals in low performing schools should focus on inspiring a shared vision and challenging the process practices. It is recommended that principal preparation programs train students to use the five transformational leadership practices in the school setting. Universities and principal preparation programs can use this quantitative study along with other studies to revamp their leadership curriculum to develop principals who are knowledgeable and highly qualified to meet the increasing demands of the principalship.

Researchers have discovered that the leadership practices in Kouzes and Posner's Leadership Model as being highly effective (Abu-Tineh et al., 2009; Saban \& Wolfe, 2009). It is recommended that the leadership model be employed as an evaluation tool. School districts can utilize the LPI to evaluate the strengths and weaknesses of principal leaders. The results of the evaluations can be used to make adjustments in practices. Professional development and inservice trainings can be tailored to meet the needs of the individual and school district. A final 
recommendation is to provide mentors to principals in low performing schools. The mentor should be a seasoned administrator who has a proven record of success in the school setting.

Recommendations for Future Research. This study was conducted in 10 small school districts in Southwest Mississippi. Future studies could be conducted in larger school districts in Mississippi, other states in the United States, or other countries. The participants in this study consisted solely of teachers. Therefore, additional studies could include the perspectives of principal leaders. Longitudinal studies could be conducted to observe differences in leadership practices over time. This study only discussed three of the key characteristics of effective leadership programs. Future studies could investigate all six characteristics of high quality principal preparation programs. Finally, it is recommended that a qualitative component be added to future studies to augment the findings of quantitative studies.

\section{References}

Abu-Tineh, A., Khasawneh, S., \& Al-Omari, A. (2009). Kouzes and Posner's transformational leadership model in practice: The case of Jordanian schools. Journal of Leadership Education, 7(3), 265-283. doi:10.12806/v7/i3/rf10

Al-Omari, A., \& Sharaah, M. (2012). Leadership readiness among prospective school leaders in Jordan. International Online Journal of Educational Science, 4(1), 50-61. Retreived from http://www.researchgate.net

Burns, J. (1978). Leadership (1st ed.). New York, NY: Harper \& Row.

Burton, L., \& Peachey, J. (2009). Transactional or Transformational? Leadership preferences of division III athletic administrators. Journal of Intercollegiate Sport, 2, 245-259.

Chegini, M. G. (2010). The relationship between organizational culture and staff productivity in public organizations. Journal of Social Sciences, 6(1), 127-129.

doi:10.3844/jssp.2010.127.129

Coladarci, T., Cobb, C., Minium, E., \& Clark, R. (2011). Fundamentals of statistical reasoning in education (3rd ed.). Hoboken, NJ: John Wiley \& Sons.

Crum, K., Whitney, H., \& Myran, S. (2009). Best practices of successful elementary school leaders. Journal of Educational Administration, 48(1), 48-63.

doi:10.1108/09578231011015412

Davis, S., \& Darling-Hammond, L. (2012). Innovative principal preparation programs: What works and how we know. Planning and Changing, 43(1/2), 25-45.

Dillon, S. (2010, January 31). Obama to seek sweeping change in no child law. The New York Times, p. A1. Retrieved from http://www.nytimes.com/2010/02/01/education/01 child.html?ref=nochildleftbehindact 
Finnigan, K. (2010). Principal leadership and teacher motivation under high-stakes accountability policies. Leadership and Policy in Schools, 9, 161-189. doi:10.1080.15700760903216174

Gulcan, M. (2012). Research on instructional leadership competencies of school principals. Education, 132(3), 625-635.

Hallinger, P. (2011). Leadership for learning: Lessons from 40 years of empirical research. Journal of Educational Administration, 49(2), 125-142. doi:10.1108/09578231111116699

Hess, F., \& Kelly, A. (2005). The politics of principal preparation reforms. Education Reform, 19(1), 155-180.

Hoy, W. K., \& Miskel, C. G. (2008). Educational Administration: Theory, Research, and Practice (8th ed.). New York, NY: McGraw-Hill.

Huff, T., Brockmeier, L., Leech, D., Martin, E., Pate, J., \& Siegrist, G. (2011). Principal and school-level effects on student achievement. National Teacher Education Journal, 4(2), 67-76.

Kantabutra, S. (2010). Vision effects: A critical gap in educational leadership research. The International Journal of Educational Management, 24(5), 376-390. doi:10.1108/09513541011055956

Knab, D. (2009). A comparison of the leadership of principals of making middle grades work schools as measured by the leadership practices inventory. Academic Leadership Journal, 7(3). Retrieved from http://www.academicleadership.org

Kouzes, J., \& Posner, B. (2003). The leadership practices inventory (LPI): Self-and observer instruments (3rd ed.). San Francisco, CA: Jossey-Bass.

Kouzes, J. M., \& Posner, B. Z. (2007). The leadership challenge (4th ed.). San Francisco, CA: Jossey-Bass.

Kouzes, J., \& Posner, B. (2009). To lead, create a shared vision. Harvard Business Review, $87(1), 20-21$.

Lee, A. (2008). Incentive interview: An expert in rewards and recognition. Incentive Publishing. Retrieved from http://www.lexisnexis.com

Leithwood, K., Aitken, R., \& Jantzi, D. (2006). Making school smarter (3rd edition ed.). Thousand Oaks, CA: Corwin. 
Leithwood, K., Harris, A., \& Hopkins, D. (2008). Seven strong claims about successful school leadership. School Leadership and Management, 28(1), 27-42. doi:10.108011363243070180060

MacNeil, A. J., Prater, D. L., \& Busch, S. (2009). The effects of school culture and climate on student achievement. International Journal of Leadership in Education, 12(1), 73-84. doi:10.1080/13603120701576241

Marzano, R., Waters, T., \& McNulty, B. (2005). School leadership that works: From research to results. Alexandria, VA: Association for Supervision and Curriculum Development.

Masumoto, M., \& Brown-Welty, S. (2009). Case study of leadership practices and school community interrelationships in high-performing, high-poverty, rural California high schools. Journal of Research in Rural Education, 24(1), 1-18.

Maulding, W., Townsend, A., Leonard, E., Sparkman, L., Styron, J., \& Styron, R. (2010). The relationship between emotional intelligence of principals and student performance in Mississippi public schools. Academic Leadership, 8(4).

McKibben, S. (2013). Do local-level principal preparation programs prevent principal turnover? The Public Purpose, 11, 69-85.

Mississippi Department of Education, Office of Accreditation. (2009). State accountability rating system. Retrieved from http://www.mde.k12.ms.us/accred/2009

Nash, W. (2010). Transformational school leadership and student achievement: A case study. Southeastern Teacher Education Journal, 3(1), 55-66.

Pepper, K. (2010). Effective principals skillfully balance leadership styles to facilitate student success: A focus for the reauthorization of ESEA. Planning and Changing, 4l(1/2), 4256.

Perilla, N. (2014). Leading the future: Rethinking principal preparation and accountability frameworks. Harvard Journal of Hispanic Policy, 26, 59-67.

Pugh, A., Fillingim, J., Blackbourn, J., Bunch, D., \& Thomas, C. (2011). Faculty validation of the leadership practices inventory with secondary school principals. National Forum of Educational Administration and Supervision Journal, 28(3), 4-11.

Roby, D. E. (2011). Teacher leaders impacting school culture. Education, 131(4), 782-790.

Saban, J., \& Wolfe, S. (2009). Mentoring principals around leadership practices. Catalyst for Change, 36(1), 2-6. 
Sadeghi, A., \& Pihie, Z. (2012). Transformational leadership and its predictive effects on leadership effectiveness. International Journal of Business and Social Science, 3(7), 186197.

Sahin, S. (2011). Instructional leadership in Turkey and the United States: Teachers' perspectives. Problems of Education in the 21 st Century, 34, 122-137.

Sawati, M., Anwar, S., \& Majoka, M. (2011). Principals' leadership styles and their impact on schools' academic performance at secondary level in Khyber Paktoonkhwa, Pakistan. Interdisciplinary Journal of Contemporary Research in Business, 3(1), 1039-1049.

Senge, P. (2008). Shared vision. Leadership Excellence, 25(3), 4.

Siegrist, G., Weeks, W., Pate, J., \& Monetti, D. (2009). Principals' experience, educational level, and leadership practices as predictors of Georgia high school graduation test results. Journal of Philosophy and History of Education, 59(1), 174-179.

Styron, R., \& Lemire, S. (2009). Principal preparation programs: Perceptions of high school principals. Journal of College Teaching and Learning, 6(6), 51-61.

Styron, R., \& Styron, J. (2011). Critical issues facing school principals. Journal of College Teaching and Learning, 8(5), 1-10.

Turan, S., \& Bektas, F. (2013). The relationship between school culture and leadership practices. Eurasian Journal of Educational Research, 52, 155-168.

Valentine, J., \& Prater, M. (2011). Instructional, transformational, and managerial leadership and student achievement: High school principals make a difference. NASSP Bulletin, 95(1), 530. doi:10.1177/0192636511404062

Versland, T. (2013). Principal efficacy: Implications for rural 'grow your own' leadership programs. The Rural Educator, 35(1), 13-22.

Yan, X. (2009). Linear regression analysis: Theory and computing. Retrieved from http://site.ebrary.com/lib/ncent/Doc?id=10361753\&ppg=22

\section{Author Biographies}

Dr. Jeff Quin is a district administrator, vocational center director, and technology director for Lawrence County School District. He has served 16 years in the school system as a teacher and an administrator. He has also taught chemistry for Copiah Lincoln Community College. His interests include transformational leadership, leadership development, principal preparation programs, school culture, and instructional technology. He holds an Ed.D in Educational Leadership from Northcentral University, a M.S. in Chemistry from the University of Southern Mississippi, and a B.S. in Chemistry from Mississippi College. 
Dr. Aaron Deris is an assistant professor in the Department of Special Education at Minnesota State University, Mankato. He has coordinated grants on inclusive practices and personnel preparation. He has worked with school districts throughout the USA to implement response to intervention in schools/districts from preK to high school. He has presented at conferences regarding working with families with children with autism, diverse family types, and inclusive practices. His current research interests include response to intervention, intervention research, effectiveness of technology in instruction, and working with families of children with disabilities. He holds a Ph.D. in Special Education from the University of New Orleans.

Dr. Greg Bischoff is an adjunct professor at Northcentral University and Houston Community College. He teaches accounting, management, and education classes and serves on doctoral committees. He is certified in Accounting and Online Teaching. He is a member of Kappa Delta Pi and Institute of Management Accountants. He holds an Ed.D in Educational Technology/E-learning from Northcentral University, a MBA in Accounting and Management from Lamar University, and a B.A. in Economics and Business Administration from University of Texas.

Dr. James T. Johnson is the Director of the Center for Research Support at the University of Southern Mississippi. His responsibilities include providing consultant services to graduate students, faculty, and staff. During the past 30 years, he has served on over 800 successful Ph.D. committees (primarily at USM, but including UMC School of Nursing, LSU School of Nursing, UAB, and South Alabama). He has served as consultant or member of numerous grants and currently serves as statistician to the National Food Service Management Institute - Applied Research Division and the Center for Stadium and Sports Security. 